\title{
Research on a Novel Teaching Model of Business Translation Based on BYOD
}

\author{
ZHAI Na* \\ Xi'an Fanyi University, Xi'an, Shaanxi, China \\ 917850448@qq.com
}

Keywords: BYOD, business translation, autonomous learning, collaborative learning.

\begin{abstract}
With the constructivist learning theory, Dewey's teaching philosophy of "learning by doing" and "lifelong learning" as the theoretical basis, BYOD-based new teaching mode of business translation can meet the needs of mobile learning, realize the cooperation of real teaching and the virtual classroom teaching and change the passive roles of teachers and students in educational informatization, so as to promote students' autonomous learning and collaborative learning and improve the teaching effect.
\end{abstract}

\section{Introduction}

BYOD (Bring Your Own Device) originated in the areas of the company, which means to use one's own devices to deal with the office work. By using the devices such as personal computer, intelligent mobile phone and tablet, one can log on the company's mailbox or online office system at the airport, hotel or cafe. In such cases, one's work is not affected by constraints of time, place, equipment, personnel and network environment. In 2009, Intel Company found that many employees worked with their own devices connected to the corporate network for work communication. In BYOD-based environment, the staff not only were more familiar with the equipment, but also had better use of fragmented time to do office works by connecting to the network inside or outside of the company. What's more, the employees bringing their own equipment could slash the cost of the company for equipment purchases. Under this background, the company began to allow and even encourage employees to use their own devices to work. BYOD represents a working style of being personalized, mobile and intelligent, in which people's life and work are connected together by a variety of intelligent terminals. Office is no longer confined to the traditional office with a PC. BYOD has become a trend, which has blurred the boundaries of the office and living hours, bettered the experience of doing office works and showed an attractive office scene for working groups [1].

Since 2010, the primary and secondary schools in USA began to advocate and encourage BYOD in teachers and students, so as to utilize resources more effectively for teaching activities. In recent years, Griffith University in Australia, University of London, Missouri University of Science and Technology, Illinois Institute of Science and Technology and the University of Scranton have carried out teaching activities based on BYOD, i.e. to make full use of teachers and students' own devices for teaching [2]. At present, part of primary and secondary schools and universities in our country have applied BYOD to carry out teaching activities, but the scale is relatively limited and the effect should be improved. BYOD-based teaching can ensure students to log on the mailbox and online learning system in different geographic locations and help to improve the students' learning initiative. BYOD can allow the teachers' and students' personalized acquisition of teaching resources with their own devices, thus to realize the interactive teaching and optimize the teaching effect. The author intends to analyze the theoretical basis for the application of BYOD in teaching and its advantages and design the BYOD-based novel teaching model of business translation to enhance the students' interest in learning and improve the teaching quality. 


\section{Theoretical basis of BYOD}

2.1 The theory of constructivism. BYOD is in accordance with the theory of constructivism. Constructivism believes that learning activities include four elements: situation, cooperation, communication and meaning construction. In the classroom situation, each student, with at least one personal equipment, will invest more attention in learning activities and experience the fun of activities for knowledge construction. At the same time, teacher-student and student-student communication or collaboration can be achieved by BYOD. Each student, as the main body of learning, can share information with others through their own devices and fulfill the meaning construction according to personalized learning requirements with the help of teachers and classmates. In this process, teacher is the guide to help students achieve personalized learning and cooperative learning.

2.2 Dewey's education philosophy of "learning from doing". BYOD coincides with Dewey's education philosophy of "learning from doing". Dewey said:" people's original knowledge and best preserved knowledge are all about how to do." [3] BYOD teaching mode encourages students to participate in learning activities, become immersed in the context and create knowledge through personal experience. Knowledge is the common product of activity, situation and culture. Only by being applied in activities and put into practice can knowledge be developed and inherited to the most.

2.3 The theory of lifelong learning. BYOD conforms to the theory of lifelong learning. Parl Lengrand, the director of Lifelong Education Bureau of UNESCO first put forward the principle of "life-long education" in 1965. After that, the advocate for establishing lifelong-learning society once occupied the top of educational searching list. The basic characteristics of lifelong learning is to expand the learning area to the house, cultural center, enterprise or other places outside of the school and make use of all available educational facilities and resources [4]. BROD can break the limitation of learning place and extend the learning period. With it, the learners can carry out lifelong learning in any place at any stage of life.

\section{The advantages of BYOD in teaching}

3.1 Meeting the practical needs of mobile learning. The number of China's mobile intelligent terminal users are increasing rapidly, among which the young people born in 1990s are the main forces. According to "The Mobile Internet Data Report of 2014" published by the independent third-party data service provider Talking Data, there were 10.6 billion mobile intelligent terminal users in China in 2014. Among them, the students have gradually become an important force of the mobile internet. The mobile terminal, being lightweight and portable, can be connected to internet quickly with powerful functions, which has become an important learning tool for students. The mobile learning will become an indispensable part of the primary education. At the same time, a variety of educational applications had turned mobile devices into a powerful learning tool. BYOD, combined with traditional classroom teaching, can promote the continuous development of mobile learning. Supported by the administrative departments of the school, BYOD can be adopted to fulfill students' constant needs of mobile learning.

3.2 Integrating virtual teaching with traditional classroom teaching. The application of BYOD has to be supported by multimedia technology and digitalized learning resources, combined with classroom teaching, case study, artifact evaluation and practical innovation activities and guided by the principles of "virtual teaching and real classroom teaching integration"[5]. The virtual teaching and real classroom teaching, both of which have their advantages and limitations, can support each other and complement each other. The virtual classroom has not only expanded the covering areas of real classroom teaching but endowed the learning with more diverse forms. Meanwhile, the real classroom teaching can make up the disadvantages of virtual teaching such as the lack of peer coaching, cooperation and collaboration, thus to support the deep interaction and emotional communication between teachers and students. 
3.3 Changing the passive role of teachers and students in educational Informatization. In the context of BYOD, teachers and students are no longer the demanders and users of informatization facilities and resources. They can introduce their own informatization equipment to the teaching process for effective application rather than depend solely on the state and school's funding for upgrading. What's more, BYOD enables teachers and students to gain educational information and resources at any needed time by preferred means. Every teacher and student are converted into active informatization builders rather than passive users of informatization products.

\section{Design and evaluation of BYOD-based new teaching model of business translation}

The author selected 40 students majoring in business translation for practice with the teaching task of "network-based translation of medical products". The teaching goal was to let students be skilled in the use of mobile devices to assist the process of business translation, be familiar with the workshop collaboration of translators and complete the translation task. In order to ensure the consistency of student-end mobile devices, the teaching practice adopted Android mobile phone as an example. There was stable wireless network coverage in the classroom. Students were equipped with Android intelligent mobile phones and each mobile phone was equipped with the application software required in the process of translation: Youdao Dictionary, Baidu and QQ (with the established class communication group for business translation). Before the teaching practice, the teacher and students had accepted a training in the use of mobile device (Android intelligent mobile phone) and application software.

The classroom consisted of three parts: student end, server end and teacher end. The student end referred to Android intelligent mobile phone. The teacher end included the laptop and projector equipped in the classroom; the server end was the connection between teachers and students. The teacher could send the electronic information-the translation task to the server for transmission and students' reception. The server could also store information besides its connecting function. By storing the information of both sides of teaching process, the serve could produce electronic archives. Both teachers and students could apply for their own personal accounts to login and consult the information or data in the teaching. Such consultation was not confined to the classroom teaching and could be made through BYOD in any place at any time after class wherever there was an access to internet.

In teaching practice, the teacher sent the translation task of medical product instruction to the server through the laptop. The server stored the file immediately after reception to produce electronic archives, and forwarded the information to the students of the Android mobile phone. The students received the task from the server, opened Youdao Dictionary to consult the translation of some difficult terminologies. For some translation which were difficult to reach agreement, the students could search through Baidu to select translation with high acceptance rate. Students could use the QQ communication group of business translation to distribute the translation task, discuss difficult words and cooperate with each other to achieve the best translation. Finally, students would feedback the best translation to the server, which would be sent to the teacher's laptop by the server after filing. The teacher could revise the translations of different groups and sent them back to students through the server. At last, the best translation could be displayed by the projector. In this teaching practice, BYOD encouraged the students' autonomous learning, strengthened the interaction between teachers and students and promoted the teaching effect. Moreover, students can cooperate and share information with other learners to finish tasks assigned by the teacher.

With the implementation of the new teaching mode, the students' learning enthusiasm has been significantly improved and become more interested in the learning of business translation. Due to the use of translation and interactive software, the accuracy of translation has been greatly improved, the students and teachers can communicate more smoothly and the teaching effect has been significantly improved. 


\section{Conclusion}

BYOD, as a new teaching mode, its unique perspective and distinctive features have attracted the attention from the field of higher education. But now, whether in the field of research or practical application, it is still not mature enough. The domestic and foreign researches on its application in the field of education are more at the introductive stage, both the theory and empirical research are insufficient. In practice, due to the diversity of student terminal equipment, it's difficult for the school to develop corresponding application software and the basic platforms. Finally, the traditional classroom teaching model has been deeply ingrained, students are more likely to be given a clear guidance rather than scaffolding in Learning. However, digitalized learning, mobile learning and ubiquitous learning have become inevitable trends of international education, technology should be used to assist in education to realize the best wish of "lifelong learning" and produce fundamental change and development to education.

\section{References}

[1] BaiduBaike. BYOD[EB/OL].http://baike.baidu.com/view/348696.htm,2015-04-07.

[2] H. C. Zhao and Z. L. Du, The problems and countermeasures of BYOD based on blended learning, China Educational Technology, vol. 12, pp. 126-127, 2015.

[3] J. Dewey, Democracy and Education. New York: The Free Press, 1996.

[4] Z. M. Wu, Modern international lifelong education. Shanghai: Shanghai Education Press, 1999.

[5] L. X. Zhang and L. X. Zhang, The types and functions of teaching activities in virtual classroom, E-education Research, vol. 6, pp. 66-69, 2010 